\title{
Surgical treatment of middle third fracture clavicle in adults by pre-contoured locked plate
}

Al-Hussein Mohamed Adham ${ }^{1, *}$ MSc; Mahmoud Seddik Hassan ${ }^{2}$ MD ; Mohamed I.Abulsoud ${ }^{2}$ MD

*Corresponding Author:

Al-Hussein Mohamed Adham

husseinmadham@gmail.com

Received for publication November 19, 2020; Accepted january 27, 2021; Published online january 27, 2021.

Copyright 2020 The Authors published by Al-Azhar University, Faculty of Medicine, Cairo, Egypt. All rights reserved. This an openaccess article distributed under the legal terms, where it is permissible to download and share the work provided it is properly cited. The work cannot be changed in anyway or used commercially.

doi: 10.21608/aimj.2021.50376.1357

${ }^{1}$ Orthopedic Surgery Department, Police Authority Hospitals,Cairo, Egypt.

${ }^{2}$ Orthopedic Surgery Department, Faculty of Medicine, Al-Azhar University, Cairo , Egypt.

\begin{abstract}
Background: The clavicle is one of the bones that are most commonly fractured in the body. In adults, clavicle fractures represent 5-10\% of all fractures and $35 \%$ of shoulder girdle fractures. Although most clavicular fractures may be treated nonoperatively, there is still a debate about the best therapy option for displaced mid-shaft clavicle fracture.

Aim of work: to investigate the results of surgical fixation of displaced middle-third fracture clavicle by the anatomical pre-contoured locked plate in young adults.

Materials and Methods: This research involved 20 adult patients with a recent middle-third clavicle fracture. Results were assessed after 1 year according to the Disabilities of the Arm, Shoulder, Hand score (DASH).

Results: The average age of the patients was 37 years old $(25-52$ years), all of them were males, All the fractures achieved union at 9 weeks (8-14 weeks ) postoperatively with no cases of implant failure, The average DASH score became15.3, 18 patients had no disabilities (90\%), 1 patient had a mild disability (5\%), 1 patient had a moderate disability (5\%). 18 patients $(90 \%)$ returned to their work within 3 months postoperatively, with no cases of deep infection with 1 case of superficial infection.

Conclusion: Surgical treatment of displaced middle-third clavicle fracture in young adults by pre-contoured locked plates is an optimum procedure resulting in excellent functional outcomes, with a quicker return to the normal activities.

Keywords: Clavicle; fracture; mid-shaft; operative; locked plate.

Disclosure: The authors have no financial interest to declare in relation to the content of this article. The Article Processing Charge was paid for by the authors.

Authorship: All authors have a substantial contribution to the article.
\end{abstract}

\section{INTRODUCTION}

One of the most fractured bones in the body is the clavicle. In adults, clavicle fractures account for 5 to $10 \%$ of all fractures and $35 \%$ of shoulder girdle fractures. The clavicle is vulnerable to fracture because of its subcutaneous location and because of its S-shape which makes it unable to handle axial compression. ${ }^{1}$ In the mid-shaft of the bone, the majority of clavicular fractures ( $80 \%$ to $85 \%)$ occur. $^{2}$ A fall on the ipsilateral shoulder resulted in the most common mechanism of injury. ${ }^{3}$

Conservative treatment was and still recommended for non-displaced clavicular fractures in adults in the form of immobilization in an arm sling or figure-of- 8 bandage with early rehabilitation. ${ }^{4,5,6}$ The figure-of- 8 bandage is recommended for fractures of the dominant extremity (to allow hand freedom) and the arm sling for fractures of the non-dominant extremity. $^{\text {? }}$

Although most clavicle fractures can be nonoperatively handled, there is still a debate about the best therapy for displaced mid-shaft clavicle fracture. Without operative treatment, nonunion rates are as high as $15-21 \% .^{8,9,10}$
Several researches have compared operative and non-operative therapy of clavicular fractures in adult athletes, which show substantial postoperative strength benefits, functional outcomes, quicker time for returning to normal activity, and decreased nonunion rates with operative treatment. ${ }^{11,12,13,14}$ Operative treatment can be performed either by open or closed reduction with a plate or intramedullary fixation respectively.

Intramedullary fixation is a less invasive method, with a smaller surgical scar providing better cosmesis. For its removal, there is less need for reoperation. Intramedullary fixation has its disadvantages which include potential migration and breakage of intramedullary device, the possibility of skin irritation, and failure to control axial length and rotation, particularly in comminuted fractures that in return may lead to nonunion or malunion. ${ }^{15}$ Because of these potential disadvantages plate fixation is considered to be the preferred method by many surgeons. ${ }^{16}$

Plate fixation provides instant rigid stabilization and facilitates an early return to normal activity and somehow considers the golden procedure for 
operative treatment. ${ }^{17,18}$ The most common complaint related to plate fixation is symptomatic hardware prominence that may necessitate its removal after bone healing. ${ }^{19}$ Other related complications to plate fixation include increased risk of infection, implant failure, and neuropathy of supraclavicular nerve. ${ }^{20,21}$

\section{MATERIALS AND MATERIALS}

Patients were recruited from the Orthopaedic Department at AL-Azhar University Hospitals and Nasr City Police Hospital, Cairo, Egypt. From January 2017 to June 2018 we collected 20 patients including adult patients with a recently displaced mid-shaft fractured clavicle. Informed approval has been gained from all sufferers involved in the research.

We conducted this prospective study on 20 adult patients (Table 1). All patients involved in this study were males $(100 \%)$. The average patient age was 37 years, ranging from 25 to 52 years of age. 14 patients had right-sided fractured clavicle $(70 \%)$ and 6 patients had left-sided fractured clavicle $(30 \%)$. The mode of trauma was road traffic accidents in 14 patients $(70 \%)$, falls on the ground in 5 patients $(25 \%)$, and direct trauma in 1 patient $(5 \%)$.

\begin{tabular}{||c|c||}
\hline Age (Year) & $\mathrm{n}(\%)$ \\
$25-30$ & $7(35)$ \\
$31-50$ & $11(55)$ \\
$>50$ & $2(10)$ \\
& 37 \\
Average age & \\
\hline Sex & $20(100)$ \\
Male & $0(0)$ \\
Female & \\
\hline Side affected & $14(70)$ \\
Right & $6(30)$ \\
Left & \\
Mechanism of trauma & $14(70)$ \\
Road traffic accident & $5(25)$ \\
Fall on ground & $1(5)$ \\
Direct trauma & \\
\hline
\end{tabular}

Table 1: Characteristic features of the studied twenty patients.

The patients were complaining of intense onset of pain in the shoulder girdle following trauma and a restricted range of shoulder motion. The history of mode and time of trauma was taken. On physical examination, the affected side was tender, deformed because of the tenting of the overlying skin by the displaced fracture. The neurovascular examination was done to exclude any neurovascular bundle affection.

A complete trauma survey for poly-trauma patients was done to exclude any life-threatening conditions. Anteroposterior (AP) view and a $45^{\circ}$ cephalic tilt view (Serendipity view) have been obtained to make a diagnosis and plan for treatment.
General resuscitation for poly-trauma patients and management of any emergency injuries was done. The injured limb was immobilized in an arm sling till the time of operation.

Operative procedure:

All cases were operated on under general anesthesia. They were operated on a radiolucent table in a semisitting "beach chair" position. The entire shoulder girdle, involving the sternum, was prepared and draped. All patients received intra-venous one gram third-generation cephalosporin (Ceftriaxone) two hours before the operation as antibiotic prophylaxis.

A straight superior incision was created just overlying the fracture location, Subcutaneous dissection has been bluntly conducted to identify the supraclavicular nerves and spare it wherever possible. To facilitate the conservation of this layer during wound closing, the platysma layer was sharply incised along the anterior border.

A pre-contoured locked anatomical plate was implemented to the upper surface of the clavicle for definitive fixation. Special attention was given when drilling the clavicular inferior surface to avoid vascular injury. Appropriate length of the screw was confirmed by a depth gauge and confirmed by fluoroscopy by the end of surgery. The general rule of placing at least 6 purchase cortices on each side of the fracture was followed. The fascia and the skin were closed in layers.

The arm was put in a standard sling for comfort after surgery. A post-surgical X-ray was obtained to be the baseline for further radiological assessment. All patients were viewed postoperatively at the fracture clinic for 14 days. The wound was examined, followup radiographs were obtained, the sling of the arm was discarded and gentle pendulum exercises were allowed. They were seen every 2 weeks and assessed with radiographs for the bony union. Once the radiological union of the fracture was accomplished, the patients were instructed to begin resisted and strengthening activities for one month.

After one year postoperatively, the patients were assessed functionally using the Disabilities of the Arm, Shoulder, Hand (DASH) Score. ${ }^{22}$ The DASH score is a functional shoulder evaluation tool of 100 points in which lower scores represent improved function. Four distinct subscales are combined: no disability (0-24), mild disability (25-49), moderate disability (50-74), marked disability (75-100).

\section{RESULTS}

In this research, across the duration from January 2017 to June 2018, 20 adult patients with recent displaced middle third fracture clavicle were included, and they underwent surgical fixation by pre-contoured anatomical locked plate. After one year follow-up period, all patients had bone union with an average time to union 9 weeks ranging from 8 to 14 weeks (Figure 1). Functional results according to Dash Score, 18 patients had no disabilities (90\%), 1 patient had a mild disability (5\%), 1 patient had a moderate disability (5\%) and no patient had marked disability $(0 \%)$. The average 
of the Dash score was 15.3 ranging from 5 to 50.18 patients returned to their work after 3 months (90\%), 1 patient after 4 months (5\%), and 1 patient after 6 months (5\%) (Figure 2).

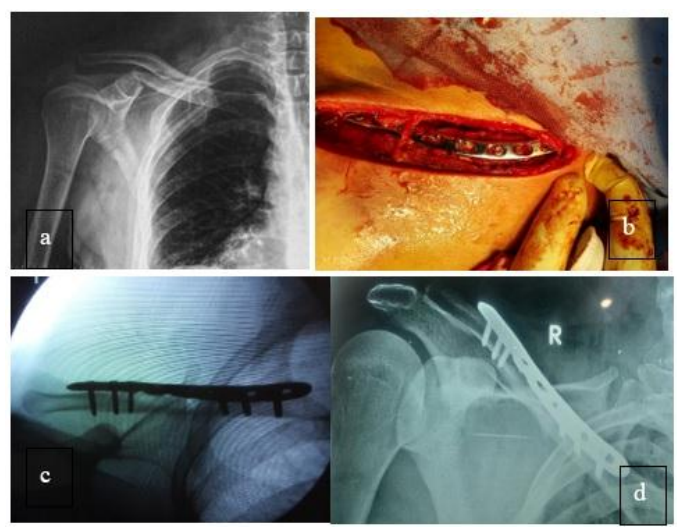

Fig. 1: (a) Preoperative radiograph anteroposterior (AP) view of a right midshaft clavicle fracture. (b) Intra-operative photo after fixation with preserved supraclavicular nerve. (c) Fluoroscopic image after fixation. (d) Follow-up radiograph showing bone union 10 weeks after the operation.
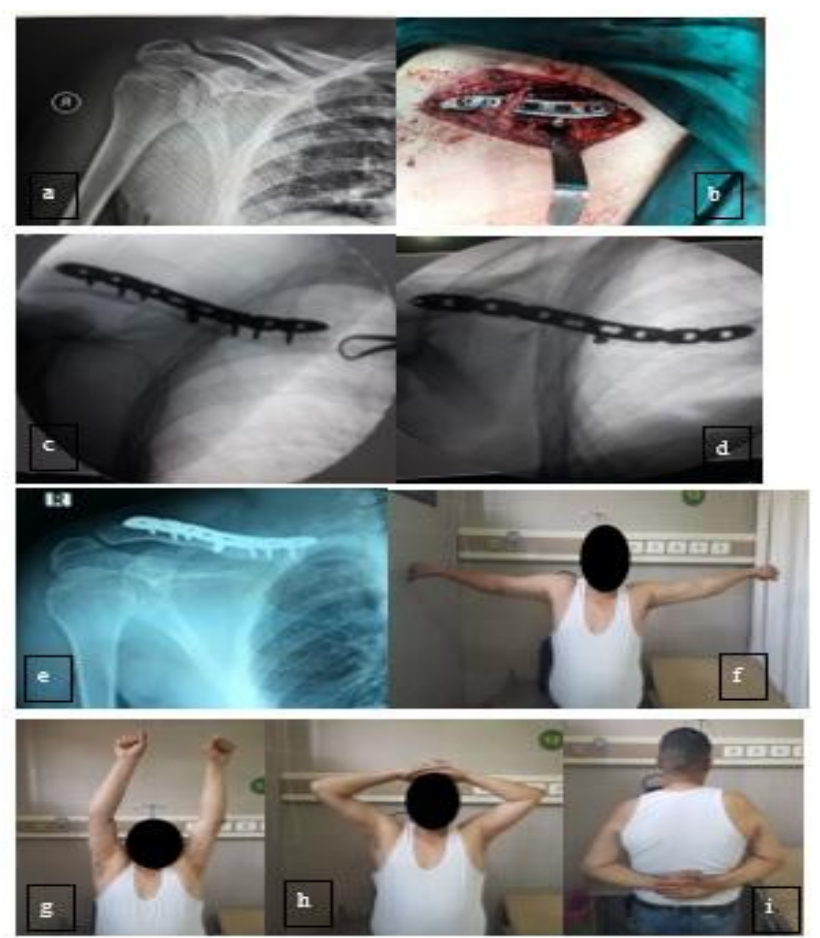

Fig. 2: (a) Preoperative radiograph anteroposterior (AP) view of a right midshaft clavicle fracture. (b) intraoperative photo after open reduction and internal fixation by a pre-contoured locked plate with preservation of the supraclavicular nerve (c and d) Fluoroscopic images Anteroposterior and axial views show adequate reduction with stable fixation and anatomical fitting of the plate on the middle third clavicle (e) Follow-up radiograph two weeks post-operatively. (f and i) Follow-up 1 year postoperatively with a complete range of motion and back to work after 3 months.
14 patients had no complications while six patients had complications. One patient had delayed union. The other five patients had numbness of the upper chest two of them had hardware prominence while one of them had a superficial infection which was resolved by oral antibiotics and wound care.

\section{DISCUSSION}

Conservative treatment has been the main therapy for all midshaft clavicular fractures regardless of the displacement because the clavicle has excellent potential for remodeling. Non-operational therapy using figure-of- 8 bandage acceptably aligns the displaced fracture and achieves a good realistic result. However, the latest meta-analysis showed higher non-union prevalence for non-operatively diagnosed displaced fractures $(15 \%)$ than operatively $(2.2 \%)$ with recent internal fixation techniques. ${ }^{8}$

Cesare et al. treated 100 patients suffering from closed displaced middle third fracture clavicle nonsurgically. ${ }^{23}$ They found that of the 100 fractures, ninety-seven recovered. The estimated recovery time for the fractures became 9 weeks (range 812 weeks). The mean disability of the arm, shoulder, and hand (DASH) score became 24 (range 0-78) and, as per this score, 81 patients had outstanding clinical outcomes, 12 were good, 5 were average, and 2 were bad. Three fracture nonunions were noticed. In all instances, the variable residual prominence correlated with a minor clavicular shortening of the bone profile was evident.

Sachin et al. surgically treated 30 patients suffering from the middle third fracture clavicle by locking plate. ${ }^{24}$ Of the 30 patients with clavicle fracture in the mid-shaft, the majority were between 15 and 35 years old $(66 \%)$, All patients in this study were males. According to the mechanism of injury, 15 cases were road traffic injuries, 12 patients were attributed to falling on the shoulder and 3 cases were due to direct assault. This study didn't pose any significant complications. By the completion of 10 weeks (90\%) and among 10 and 12 weeks (6.66\%), the majority of instances were united. Fracture union took an average time of 10 weeks (8-12 weeks). Only two $(6.66 \%)$ patients have a superficial skin infection and one (3.33\%) had nonunion.

Yogesh et al. surgically treated 20 patients suffering from midshaft fractures by locking plate. ${ }^{25}$ The age ranged from 19 to 55 years in this series, with an average age of 27 years. Male predominance was present. Male: The proportion of females was 9:1. A vehicular accident $(55 \%)$ and a fall from height (45 $\%)$ were the most common form of injury. The left side was affected in the majority of patients $(65 \%)$. According to complications, there were no complications detected except for one patient with implant expose. In this study, fractures were united in seven to eight weeks in most of the cases. The average time for the union is 7.3 weeks. The mean Final DASH Score about 32. By the end of followup, all 20 patients had a complete range of motion without any restrictions. The majority of all 20 patients had a positive outcome, 17(85\%) and 2(10 
$\%)$ had an outstanding result, $1(5 \%)$ had bad results as per the DASH score.

A study was made by Mohsen et al. to assess the results of operative treatment with a plate and conservative treatment of the middle third fractured clavicle. ${ }^{26}$ In the operative community, 26 patients $(73.3 \%)$ were pleased with the treatment and 9 patients $(25.7 \%)$ were disappointed with the outcome of the treatment. In the conservative community, twenty patients $(66.7 \%)$ were pleased with the treatment and 10 people $(33.3 \%)$ were disappointed. Much discontent resulted from clavicle appearance $(13.8 \%)$ and mobility constraints during hard work with a weaker ability than the opposite hand (16.9\%). The overall satisfaction of patients has been established by a separate questionnaire measuring functional outcomes according to the DASH score. The mean DASH score became 24.6 (range 0-88) for the operative community and 22.7 (range $0-87$ ) for the conservative community, with no substantial distinction between the two groups. The overall union time between the operative patients in the conservative group was estimated at 8.5 weeks and 8.8 weeks, suggesting no substantial gap between the two groups. Five patients $(14.3 \%)$ in the operative community had surgical site infections, while in the conservative community there were no cases of infection. Two patients $(5.7 \%)$ of the operative community and four patients of the conservative community $(13.3 \%)$ suffered from nonunion. The two parties didn't make any noticeable difference. Eighteen patients $(60 \%)$ in the operative community and seven $(20 \%)$ in the conservative community showed delayed union. Among the non-surgical care community, the delayed union became more popular.

In patients with midshaft clavicular fractures treated with pre-contoured anatomical locking compression plate (ALCP) versus reconstruction locking compression plate (RLCP), Fang et al. conducted a research to evaluate the occurrence of mechanical defects, functional and radiological results. ${ }^{27}$ The study included a hundred and six patients with displaced clavicular mid-shaft fractures managed with plate fixation and who underwent a minimum follow-up duration of 6 months. 53 patients managed with ALCP and 53 patients managed with RLCP. There were no substantial variations in clinical results among the 53 matched patient pairs in the ALCP and RLCP groups. A maximum range of motion compared to the contralateral shoulder was reached by forty-eight $(90.6 \%)$ ALCP and fortyseven $(88.7 \%)$ RLCP patients. Any degree of chronic pain at resting was suffered by seven (13.2 $\%)$ ALCP and five (9.4\%) RLCP patients. There were implant removals in twenty-six $(49.1 \%)$ ALCP and thirty $(56.6 \%)$ RLCP patients. Through 0-3 months of follow-up, six $(11.3 \%)$ patients in the RLCP group were found to include post-operative implant deformation compared to zero $(0 \%)$ in the ALCP group. Five of the six patients, including progressive angulation of the reconstruction plate, had fracture union. One patient suffered implant breaking and non-union following RLCP and had reoperation with grafts and revision plating using ALCP following 3 months. Functional scores in their clinics, like the Disabilities of the Arm, Shoulder, and Hand (DASH) have not been measured on a regular basis. They recommended avoiding the usage of RLCP for less durable comminuted fractures as ALCP provides greater mechanical support and a less rigorous rehabilitation program should then be followed for patients treated with reconstruction plates. For reconstruction plates, they found a higher occurrence of implant plastic deformation.

In this study, all patients involved were males (100 $\%)$. The patients' average age varied from 25 to 52 years old, being 37 years old. 18 patients returned to their work after 3 months (90\%), 1 patient after 4 months $(5 \%)$, and 1 patient after 6 months $(5 \%)$. Such information is encouraging for the use of such an implant in young active populations.

\section{CONCLUSION}

Our study has limitations. This has been a limited prospective research. To support the outcomes achieved in our research, a more study with a bigger sample size is needed in the future.

On the other side, surgical therapy of displaced middlethird fracture clavicle by pre-contoured anatomical locked plate resulted in minimal complications, short hospital stay, early return to work, and excellent functional outcomes.

\section{REFERENCES}

1. Robinson CM. Fractures of the clavicle in the adult: epidemiology and classification. J Bone Joint Surg Br. 1998; 80: 476-84.

2. Chen DJ, Chuang DC, Wei FC. Unusual thoracic outlet syndrome secondary to fractured clavicle. $J$ Trauma. 2002; 52: 398-9.

3. Stanley D, Norris S. Recovery following fractures of the clavicle treated conservatively. Injury. 1988; 19: $162-4$.

4. Jeray KJ. Acute midshaft clavicular fracture. $J \mathrm{Am}$ Acad Orthop Surg. 2007; 15: 239-48.

5. Court-Brown CM, McQueen MM, Wakefield AE. Estimating the risk of nonunion following nonoperative treatment of a clavicular. J Bone Joint Surg Am. 2004; 1359-65.

6. Eiff MP. Management of clavicle fractures. Am Fam Physician. 1997; 55: 121-8.

7. Lazarus MD. Fractures of the clavicle. In: Bucholz R.W., Heckman JD. eds. Rockwood and Green's Fractures in adults. vol 1. 5th ed. Philadelphia, Pa: Lippincott Williams \& Wilkins. 2001; 1041-78.

8. Zlowodzki M, Zelle B, Cole P, et al. Treatment of acute midshaft clavicle fractures: a systematic review of 2144 fractures: on behalf of the Evidence-Based Orthopaedic Trauma Working Group. J Orthop Trauma. 2005; 19: 504-7.

9. Canadian Orthopaedic Trauma Society. Nonoperative treatment compared with plate fixation of displaced midshaft clavicular fractures. A multicenter, randomized clinical trial. J Bone Joint Surg Am. 2007; 89: 1-10. 
10. Robinson CM, Court-Brown CM, McQueen MM. Estimating the risk of nonunion following nonoperative treatment of a clavicle fracture. $J$ Bone Joint Surg Am. 2004; 86: 1359-65.

11. Witzel K. Intramedullary osteosynthesis in fractures of the mid-third of the clavicle in sports traumatology. Z Orthop Unfall. (2007); 145: 639-42.

12. Meier C, Grueninger P, Platz A. Elastic stable intramedullary nailing for midclavicular fractures in athletes: indications, technical pitfalls and early results. Acta Orthop Belg. 2006; 72 : 269-75.

13. Morgan RJ, Bankston LS, Hoenig MP, et al. Evolving management of middle-third clavicle fractures in the National Football League. Am J Sports Med. 2010; 38: 2092-6.

14. Rabe SB, Oliver GD. Clavicular fracture in a collegiate football player: a case report of rapid return to play. J Athl Train. 2011; 46: 107-11.

15. Golish SR, Oliviero JA, Francke EI. A biomechanical study of plate versus intra-medullary devices for midshaft clavicle fixation. J Orthop Surg Res. 2008; 3: 28.

16. Zenni EJ, Jr, Krieg JK, Rosen MJ. Open reduction and internal fixation of clavicle fractures. $J$ Bone Joint Surg. 2008; 63: 147-51.

17. Van der Meijden OA, Gaskill TR, Millett PJ. Treatment of clavicle fractures: current concepts review. Journal of Shoulder and Elbow Surgery. 2012; 21: 423-9.

18. Faraud A, Bonnevialle N, Allavena C, et al. Outcomes from surgical treatment of middle-third clavicle fractures non-union in adults: A series of 21 cases. Orthopaedics \& Traumatology: Surgery \& Research. 2014; 100: 171-6.

19. Kloen P, Sorkin A, Rubel I. Anteroinferior plating of midshaft clavicular non-unions. J Orthop Trauma. 2002; 16: 425-30.
20. Ledger M, Leeks N, Ackland T. Short mal-unions of the clavicle: an anatomic and functional study. $J$ Shoulder Elbow Surg. 2005; 14: 349-54.

21. Woltz S, Stegeman S, Krijnen P. Plate fixation compared with non-operative treatment for displaced mid-shaft clavicular fractures: a multicenter randomized controlled trial. J Bone Joint Surg. 2017; 99: $106-112$

22. Hudak PL, Amadio PC. The Upper Extremity Collaborative Group (UECG) Development of an upper extremity outcome measure: the DASH (disabilities of the arm, shoulder and hand) Am J Ind Med. 1996; 29: 602-8.

23. Cesare F, Matteo N. Nonoperative treatment of closed displaced midshaft clavicle fractures. $J$ Orthop Traumatol. 2010; 11: 229-36.

24. Sachin S, Rajul G. A retrospective study on surgical management of clavicle midshaft fractures by locking plate in tertiary care center. Department of Orthopedics, Chirayu Medical College and Hospital, Bhopal, Madhya Pradesh, India. 2017; 9: 81-3.

25. Yogesh CP, Alizayaagam NH. Study of results of clavicle fractures treated with clavicle plating in adults according to dash score. International Journal of Orthopaedics Sciences. 2018; 4: 963-6.

26. Mohsen K, Mohammad F. The Comparison of Results of Treatment of Midshaft Clavicle Fracture between Operative Treatment with Plate and NonOperative Treatment. Arch Bone Jt Surg. 2014; 2: $210-4$.

27. Fang CX, Liu R, Yee DKH, et al. Comparison of radiological and clinical outcomes, complications, and implant removals in anatomically pre-contoured clavicle plates versus reconstruction plates - a propensity score-matched retrospective cohort study of 106 patients. BMC Musculoskeletal Disorders. 2020; 21:413. 